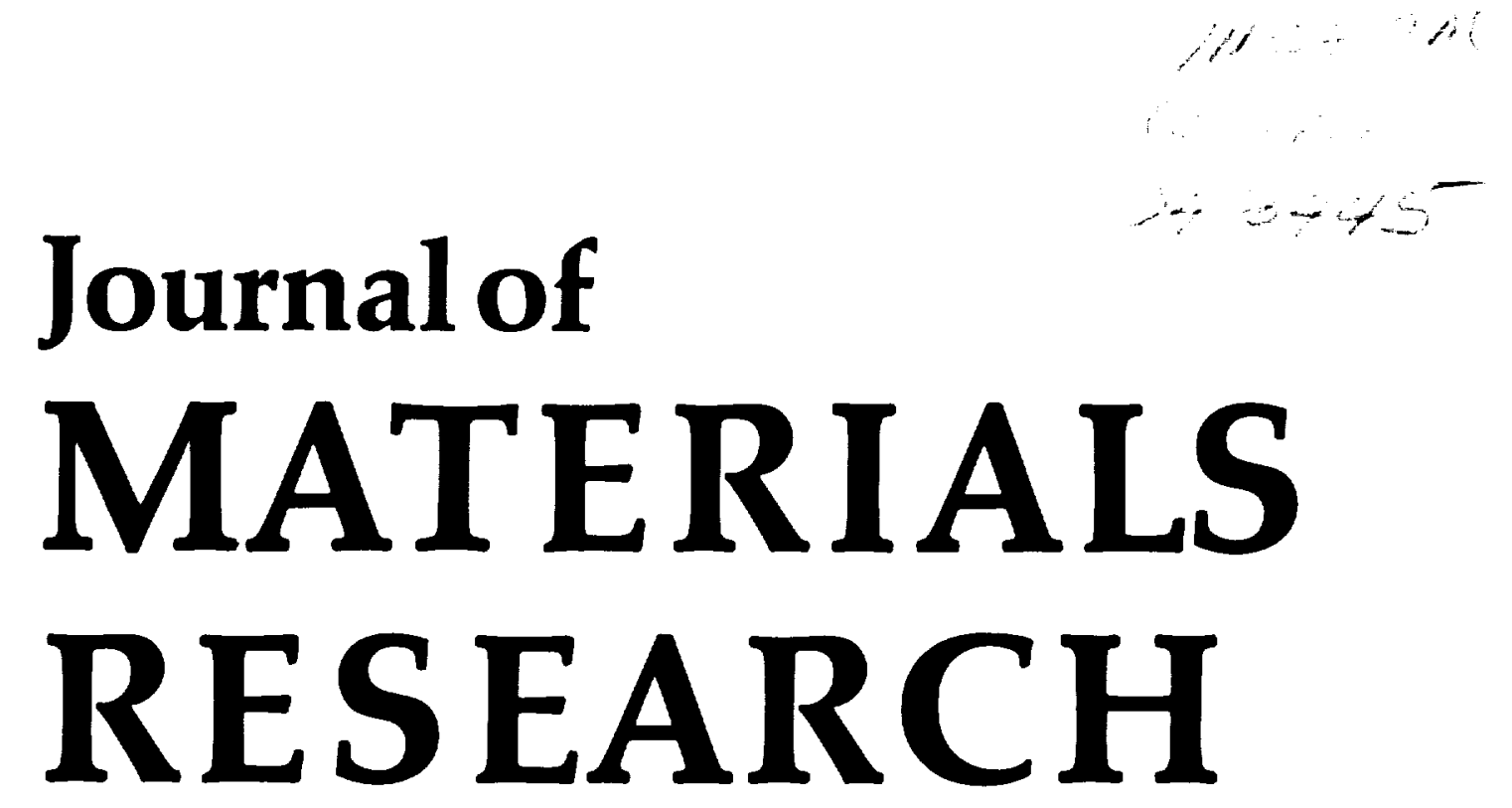

Characterization of SiC fiber (SCS-6) reinforced-reactionformed silicon carbide matrix composites

M. Singh and R. M. Dickerson

NYMA, Inc., Lewis Research Center Group, Cleveland, Ohio 44l35-319I

pp. 746-751

Volume 11, Number 3

March 1996

Published by the Materials Research Society 



\title{
Characterization of SiC fiber (SCS-6) reinforced-reaction- formed silicon carbide matrix composites
}

\author{
M. Singh and R. M. Dickerson \\ NYMA, Inc., Lewis Research Center Group, Cleveland, Ohio 44135-3191
}

(Received 26 May 1995; accepted 5 October 1995)

\begin{abstract}
Silicon carbide fiber (SCS-6) reinforced-reaction-formed silicon carbide matrix composites were fabricated using a reaction-forming process. Silicon- 2 at. $\%$ niobium alloy was used as an infiltrant instead of pure silicon to reduce the amount of free silicon in the matrix after reaction forming. The matrix primarily consists of silicon carbide with a bimodal grain size distribution. Minority phases dispersed within the matrix are niobium disilicide $\left(\mathrm{NbSi}_{2}\right)$, carbon, and silicon. Fiber pushout tests on these composites determined a debond stress of $\sim 67 \mathrm{MPa}$ and a frictional stress of $\sim 60 \mathrm{MPa}$. A typical four-point flexural strength of the composite is $297 \mathrm{MPa}(43.1 \mathrm{KSi})$. This composite shows tough behavior through fiber pullout.
\end{abstract}

\section{INTRODUCTION}

In recent years, there has been an increasing demand for high performance and lightweight composite materials for aerospace and other high temperature structural applications. Silicon carbide-based advanced ceramics and composites which show high strength and toughness, oxidation resistance, and high thermal conductivity, have attracted attention for a variety of gas turbine engine applications. ${ }^{1,2}$ Fabrication of gas turbine components requires a process with near-net or complex shape capabilities. Currently, silicon carbide matrix composites are fabricated by a number of techniques: hot pressing, ${ }^{3,4}$ polymer pyrolysis, ${ }^{5}$ chemical vapor infiltration, ${ }^{6}$ and melt infiltration. ${ }^{7,9}$ Hot pressing, hot isostatic pressing, and sintering require high temperatures for processing (typically around $1600-2000^{\circ} \mathrm{C}$ ). Also, it is very difficult to attain full density due to the constraint of the fibers, especially in the case of pressureless sintering. In addition, complex and near-net shape requirements are additional problems to overcome. In the polymer pyrolysis process, multiple infiltrations are needed. Further, this process yields microcrystalline and often microcracked matrices. ${ }^{8}$ Another widely used technique is chemical vapor infiltration (CVI) which is a very slow process requiring a long processing time (often weeks). In addition, CVI cannot yield full density; composites typically have $10-15 \%$ residual porosity. ${ }^{8}$ In the SILCOMP ${ }^{\mathrm{TM}}$ and other related processes, which are based on molten silicon infiltration, there is very little control over green body porosity, and thick interface coatings are required to prevent molten silicon attack 7,9

From the above, it is clear that the majority of current composite processing techniques are either expensive or have limitations in complex shape and near-net-shape fabrication. Therefore, it is necessary to develop a processing approach that has near-net and complex shape capabilities and that is also cost effective.

The reaction-forming process reported in this work has many advantages over the processing techniques described above. It can be used for the fabrication of silicon carbide matrix composites with large diameter monofilaments or small diameter fibers. ${ }^{10-12}$ It also provides very good control of residual phases (refractory disilicides and silicon). Since the starting material is a liquid polymer, second phases can be incorporated very easily. In this process, a microporous carbon preform containing fibers is infiltrated with molten silicon or silicon-refractory metal (molybdenum, niobium) alloys. ${ }^{10-12}$ The infiltrating materials react with the carbon and form matrices of silicon carbide, refractory disilicides $\left(\mathrm{MoSi}_{2}, \mathrm{NbSi}_{2}\right)$, and silicon. The relative amounts of these phases depend on the properties of the porous carbon preform and composition of the infiltration materials. These are controlled by the morphology and porosity of the carbon precursor matrix and the reaction conditions. This process yields composites that have full density.

The objective of this paper is to study the microstructure and mechanical properties of silicon carbide fiber (SCS-6) reinforced-reaction-formed silicon carbide matrix composites fabricated by $\mathrm{Si}-2$ at. \% niobium alloy infiltration. Electron microscopy and microprobe analysis were used to determine the overall microstructure, the distribution of niobium disilicide, and to determine if there was any incorporation of the niobium apart from the disilicide. The interfacial shear strength and room temperature flexural properties of these composites are also discussed.

\section{EXPERIMENTAL PROCEDURES}

To fabricate the composite matrix, a mixture of high char yield resin, a liquid pore-forming agent, and an 
acid catalyst is infused within a fiber preform. These fiber preforms are made by stacking eight layers of unidirectional fiber mats ( 88 fibers/inch). The resin mixture is polymerized and pyrolyzed up to $700{ }^{\circ} \mathrm{C}$ in $20 \mathrm{~h}$ to form a microporous carbon matrix. By varying the ratios of the constituents in the system, a wide variation of pore volumes, pore sizes, and porous carbon morphologies can be obtained. At the infiltration temperature $\left(\sim 1430{ }^{\circ} \mathrm{C}\right)$, the molten $\mathrm{Si}-2 \%$ niobium alloy reacts with the microporous carbon matrix to form silicon carbide. The rate of infiltration depends on the wetting of the preform by the melt which increases with increasing temperature.

Cross-sectional samples were metallographically mounted and polished for optical microscopy, scanning electron microscopy (SEM), and electron microprobe analysis (EMPA). The optical microscopy, performed on a Richert MeF3 A metallographic microscope, included interference layering in which chemical differences are enhanced in reflected light after the deposition of a thin oxide layer on the sample. SEM was performed on a JEOL JSM 840A, and EMPA was done using an ARL SEMQ microprobe. Transmission electron microscopy (TEM) thin foils were prepared using standard techniques, finishing with Ar ion beam milling. TEM was accomplished on a Philips EM400T operating at $120 \mathrm{keV}$ with a Kevex Quantum thin window x-ray energy dispersive spectrometer for chemical analysis. Fiber pushout tests were carried out on the apparatus described in Ref. 13. Flexural strengths were measured using four-point flexural tests on an INSTRON 7551 frame, and load deflection behavior was recorded using a Linear Variable Differential Transformer (LVDT) probe.

\section{RESULTS AND DISCUSSION}

\section{A. Microstructure}

Figure 1 shows a polished section of the composite formed by the infiltration of the preform with a $\mathrm{Si}-2$ at. \% niobium alloy. The uniformity of the reactionformed material reflects the well-controlled porosity of the carbon preform obtainable using the present method. The phase diagram of the $\mathrm{Nb}-\mathrm{Si}$ system ${ }^{14}$ indicates the existence of a large two-phase (liquid silicon and solid niobium disilicide) region. Because of the reaction of silicon with carbon during processing, the local concentration of silicon in the alloy melt decreases and the melt composition shifts toward the two-phase region (liquid silicon and niobium disilicide) where niobium disilicide starts to precipitate from the melt. Electron microprobe compositional dot maps of the composite (Fig. 2) showed that the niobium was incorporated in small clusters of particles in the matrix and had not diffused into or reacted with the SCS- 6 fibers. The

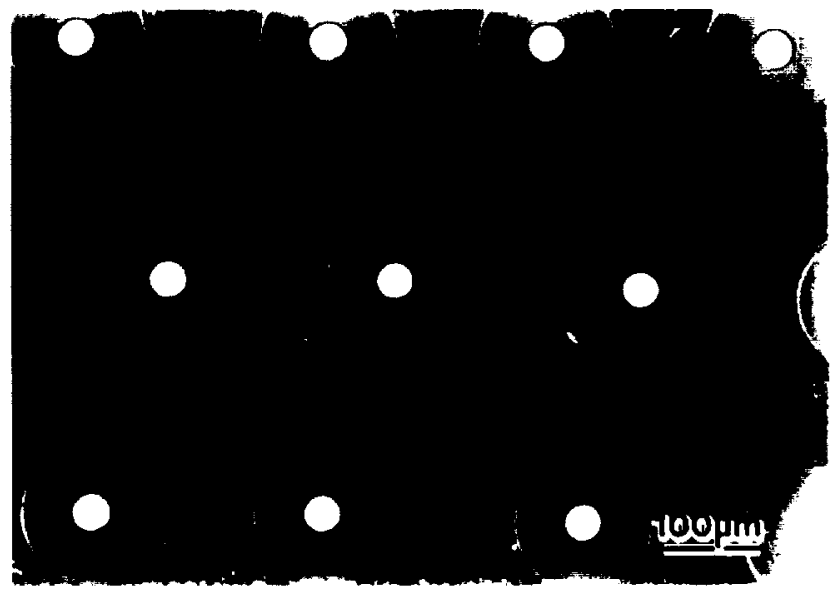

FIG. 1. Interference layering optical micrograph of composite infiltrated with a molten $\mathrm{Si}-2$ at. $\% \mathrm{Nb}$ alloy

EMPA further revealed that any residual silicon and the $\mathrm{NbSi}_{2}$ were dispersed within the matrix.

Higher magnification scanning electron images of the fiber/matrix interface (Fig. 3 ) revealed that some regions of the outermost carbon coating $(\sim 1.5 \mu \mathrm{m})$ had reacted to form scalloped regions of $\mathrm{SiC}$; however, these reactions are very limited. It was observed that the liquid resin provided a carbon coating on the fibers. The presence of this thin carbon coating coupled with the well-controlled porosity of the carbon preform is thought to be the leading contributor to the significant reduction in the reaction of alloy infiltrants with the fibers during processing. It should be noted that in other melt infiltration processed composites, $3-5 \mu \mathrm{m}$ thick interfacial coatings are required to sufficiently protect the fibers. ${ }^{79}$ The interface between the outer carbon-rich coating layer and the inner carbon-rich coating layer must be maintained to obtain good fiber pullout and composite-like behavior. ${ }^{10}$ That interface was usually undisturbed in the present approach.

\section{B. TEM Analysis}

The details of the matrix microstructure were studied using transmission electron microscopy. Optical and SEM micrographs showed a slight variation in contrast within the silicon carbide (Fig. 3). In SEM, there were two shades of contrast when backscattered electrons (BSE) were used to form an image, which suggests two slightly different average atomic numbers. Through comparison of the SEM and TEM analyses, it was determined that the regions giving the appearance of a higher average atomic number (being brighter in backscattered electron contrast) contained finer grained $\mathrm{SiC}$, while the $\mathrm{SiC}$ in the darker $\mathrm{BSE}$ regions was more coarse. The cause of this effect is not certain. The two regions were easily differentiated in the TEM (Fig. 4). The silicon carbide grain sizes in the finer regions varied 

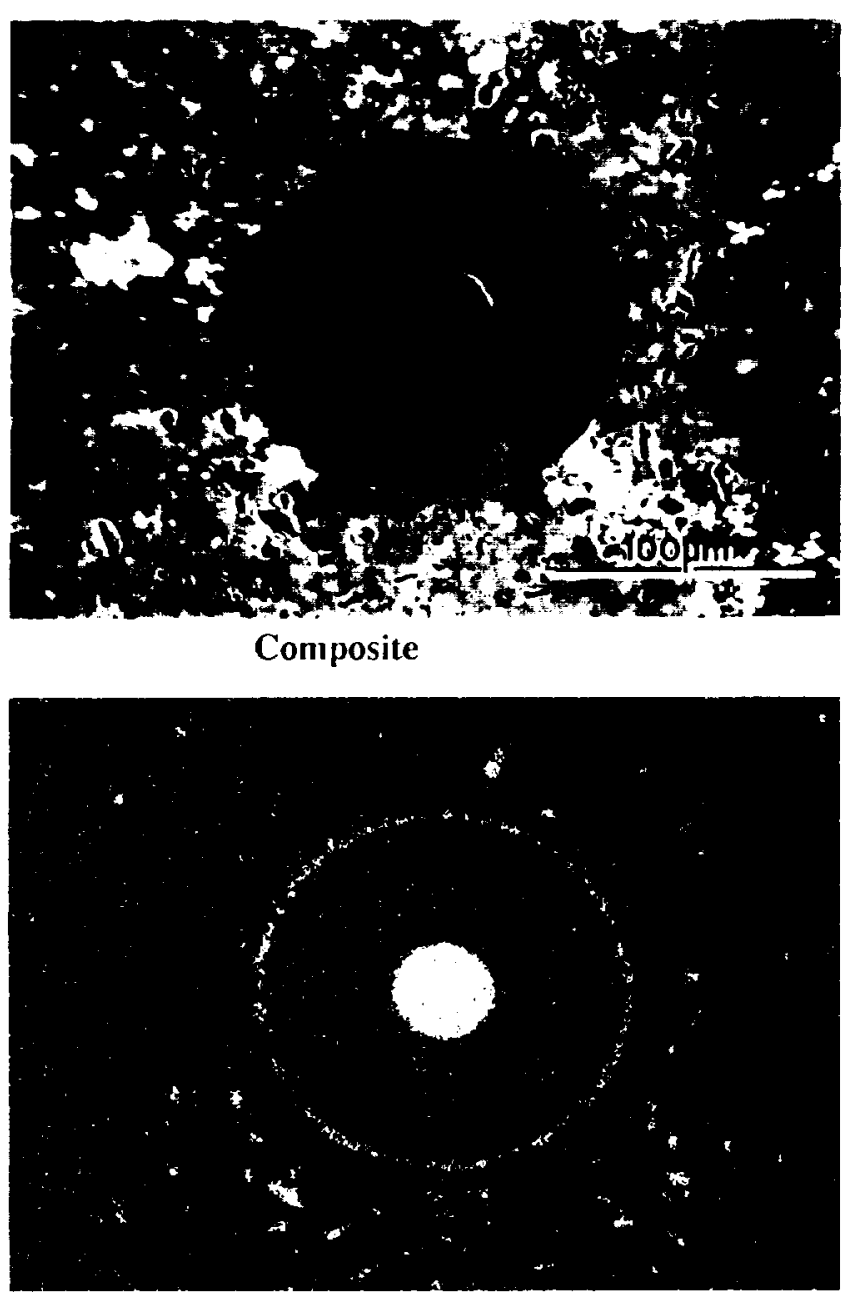

Carbon

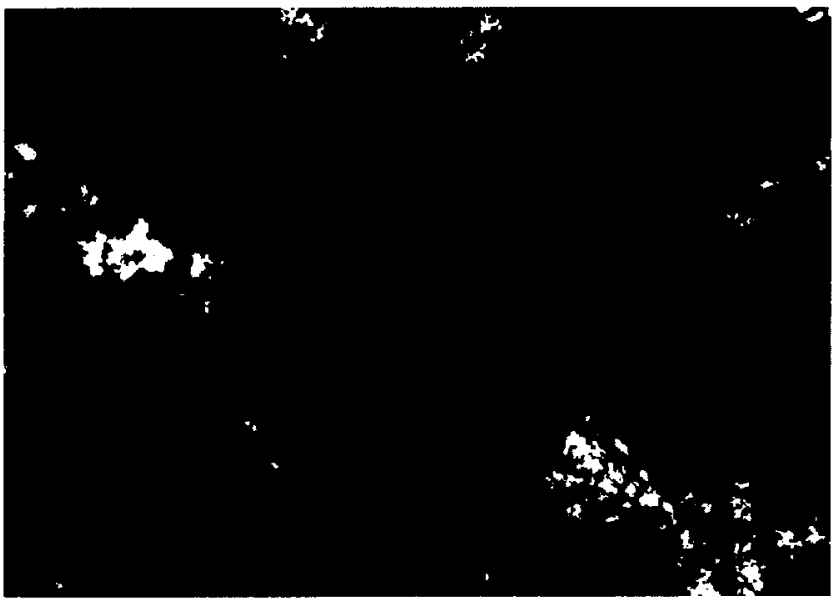

Niobium

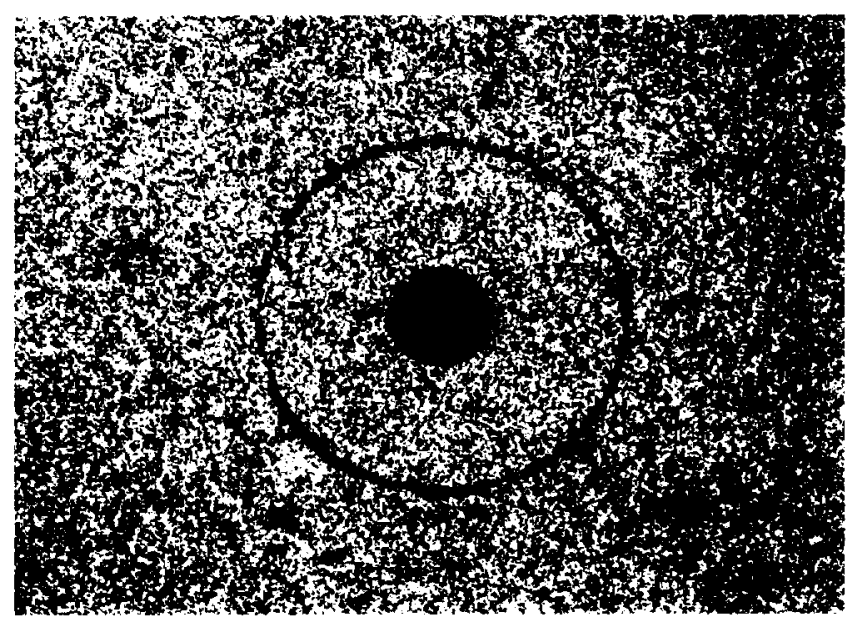

Silicon

FIG. 2. Electron microprobe images of the composite formed using $x$-ray signals from niobium, carbon, and silicon, as well as backscattered electrons (BSE's).

over a range from approximately $30 \mathrm{~nm}$ in the center of the cluster to nearly $1 \mu \mathrm{m}$ near the larger matrix material. The grain size ranges in the coarser material were narrower, generally staying between 1 and $5 \mu \mathrm{m}$. All the silicon carbide grains in the matrix were formed by the reaction of silicon-niobium alloy with carbon. We have found that the solution-reprecipitation is the dominant reaction mechanism in this system. ${ }^{12}$ Electron diffraction patterns from the silicon carbide grains were almost always consistent with the cubic $\beta$ polytype. A few grains, however, had the hexagonal $6 \mathrm{H}$ structure in coarse and fine grain regions. Both finer and coarser SiC grains were highly faulted, as is shown in Figs. 5(a) and $5(\mathrm{~b})$, respectively. The expected minority phases, $\mathrm{NbSi}_{2}$, and residual carbon were confirmed crystallographically and compositionally in the TEM. The $\mathrm{NbSi}_{2}$ grains were relatively featureless internally and irregularly shaped. Residual carbon was fibrous in structure and usually neighbored by fine-grained SiC.
TEM also revealed the fiber/matrix interface microstructure. The fiber core and surrounding carbide were identical to as-received fibers, as was the inner carbon-rich layer of the fiber/matrix interface [Fig. 6(a)]. The outer carbon-rich layer, however, often reacted with the matrix to form very fine-grained silicon carbide [Fig. 6(b)], which was essentially identical to the finer grained matrix material. The boundary between the two carbon-rich layers, characteristic of the SiC fiber (SCS6) coating system, was usually cracked in TEM thin foil samples. This indicates a relatively weak interface and possible residual stresses on the fiber by the matrix after processing.

\section{Interfacial shear strengths}

As was mentioned earlier, the silicon carbide fiber (SCS-6) used in this study has an outer carbon-rich 


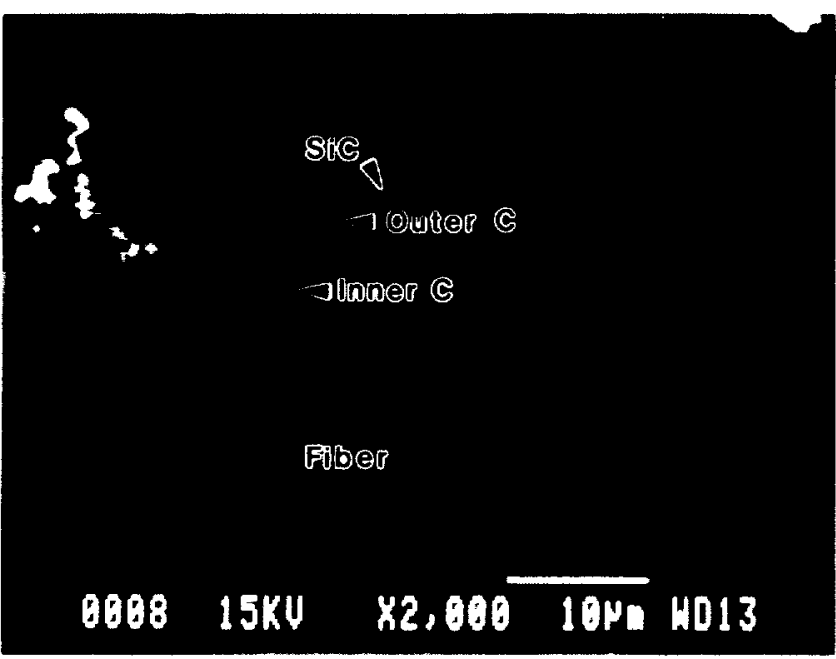

FIG. 3. Scanning electron micrograph of the fiber/matrix interface using BSE contrast showing the scalloped reaction region of the outer carbon-rich layer.

coating applied by the manufacturer. In a brittle fiberbrittle matrix composite, it is necessary that a low shear strength material separate the fiber and matrix to give good mechanical properties to the composite. Figure 7(a) shows a typical load-displacement curve for fiber pushout tests. The average debond and frictional stresses for a $0.65 \mathrm{~mm}$ thick sample are $67.2 \pm 15.1 \mathrm{MPa}$ and $60.8 \pm 14 \mathrm{MPa}$, respectively. Figures $7(\mathrm{~b})$ and 7(c) show typical micrographs of pushed-out fibers. The majority of fibers debond between the outer carbon layers of the SiC fibers (SCS-6) with some debonding occurring between the fiber and its carbon layers.

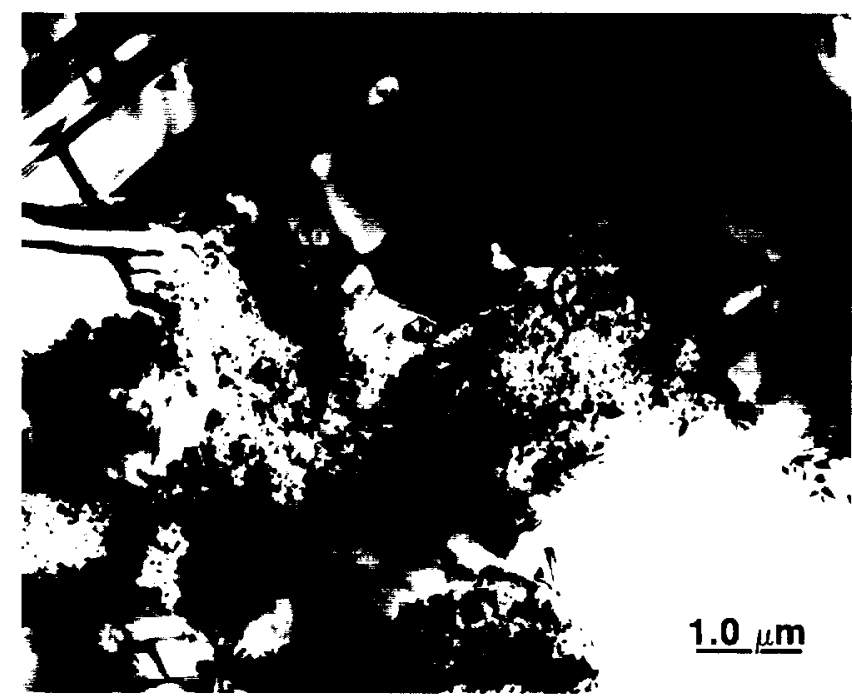

FIG. 4. Transmission electron micrograph (TEM) showing the bimodal and separate $\mathrm{SiC}$ grain size distributions.

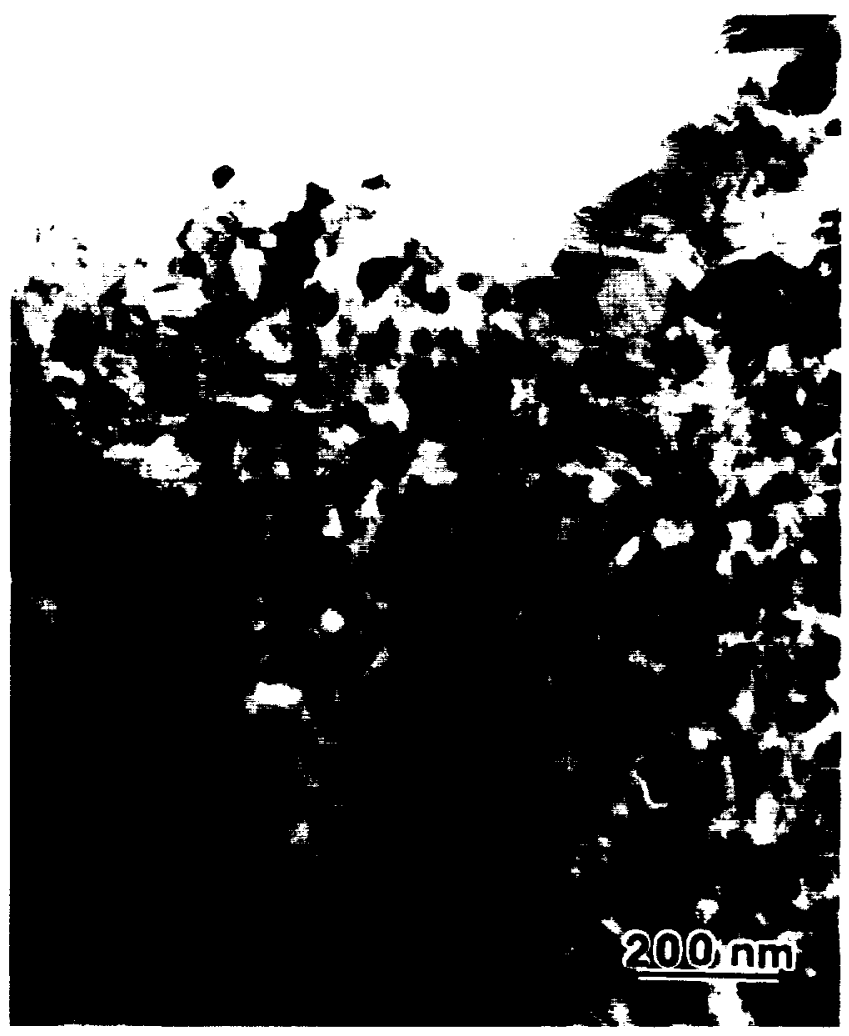

(a)

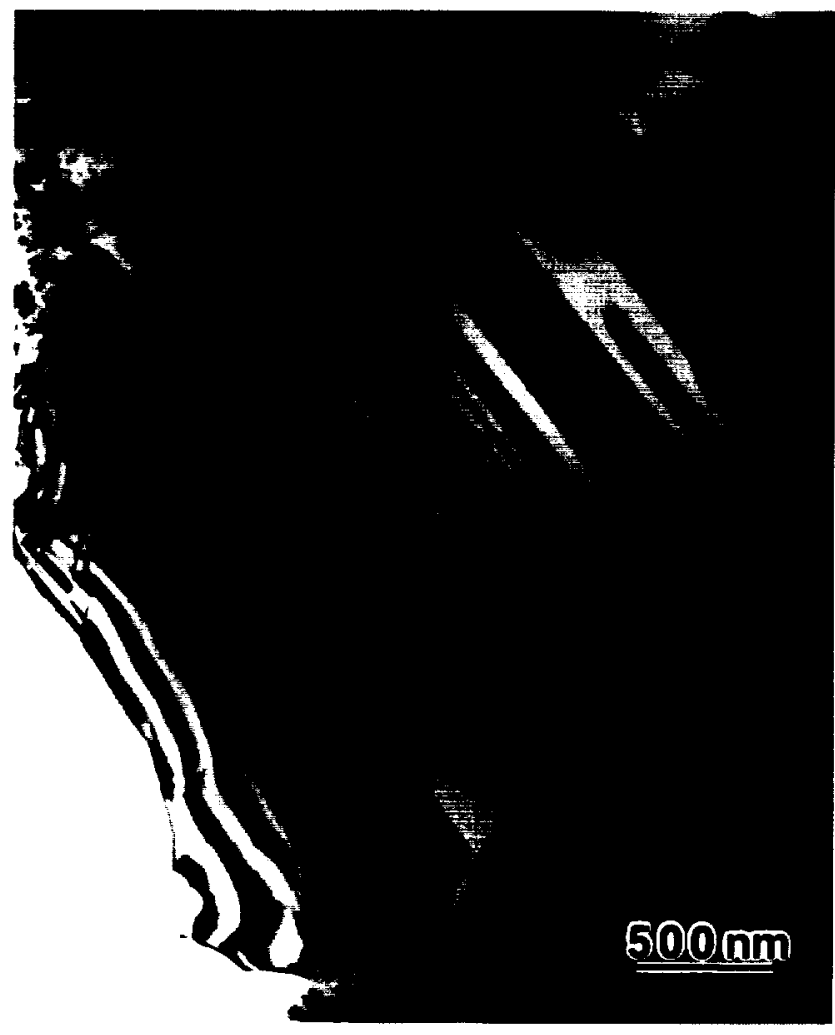

(b)

FIG. 5. Intragranular faulted microstructures shown using TEM of the finer (a) and coarser (b) SiC grains. 


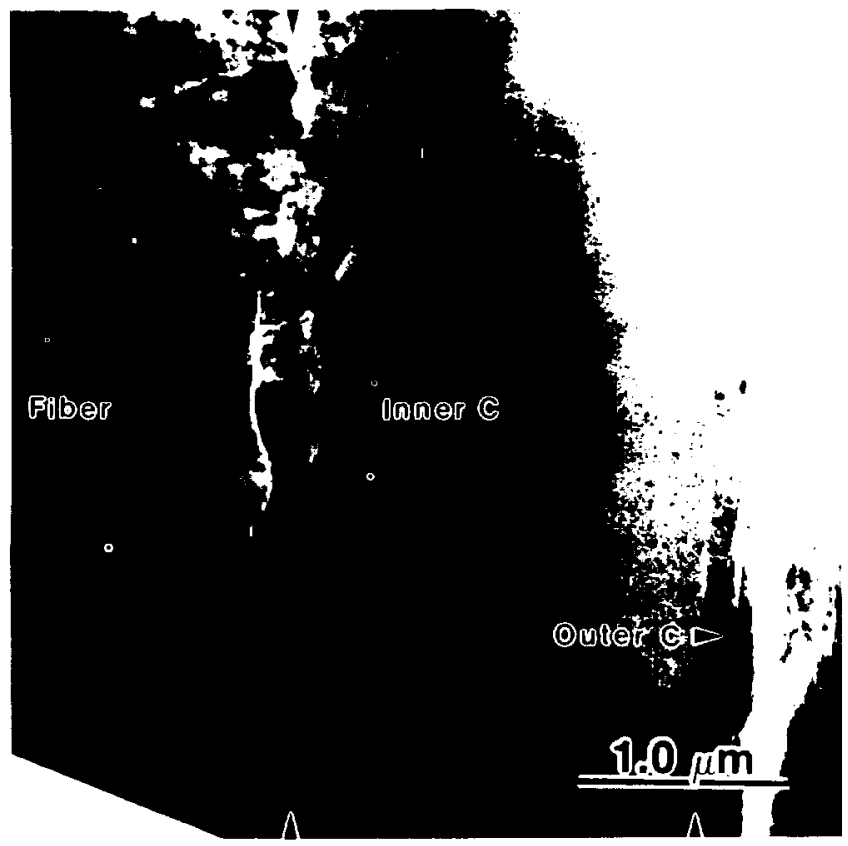

(a)

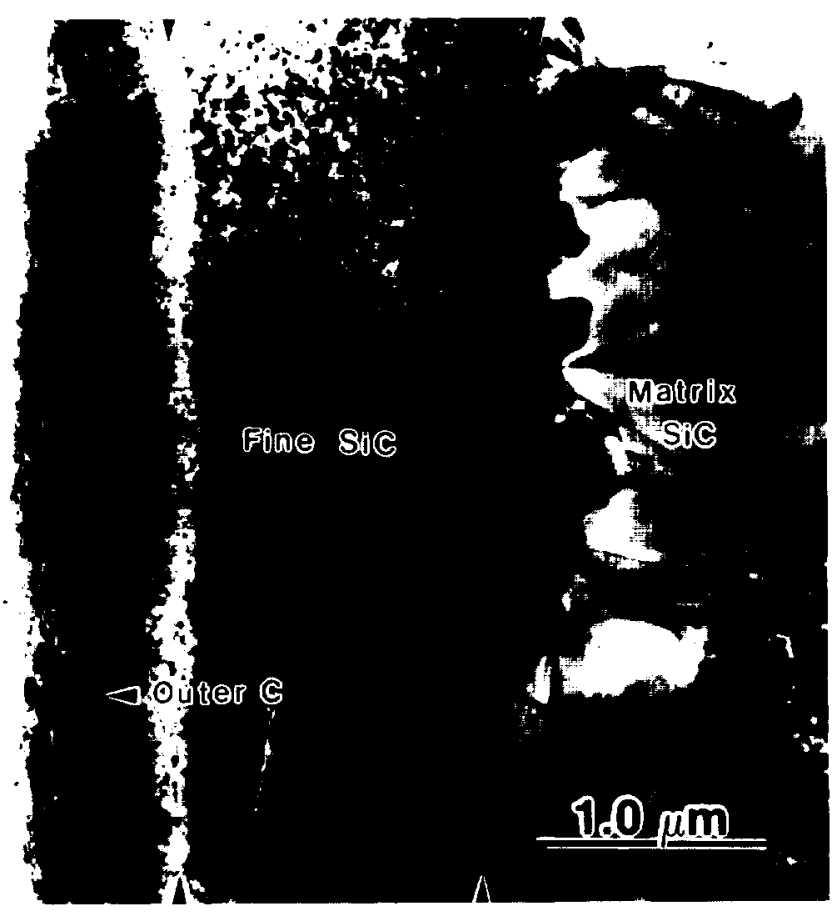

(b)

FIG. 6. Bright-lield TEM micrographs of the tiber/matrix interface. The $\mathrm{SiC}$ fiber/inner carbon-rich layer (a) and outer carbon-rich layer/matrix $\mathrm{SiC}$ regions are shown in (b).

\section{Flexural properties}

The mechanical behavior of the silicon carbide fiber (SCS-6) reinforced-reaction formed silicon carbide composites was determined using four-point flexural tests at room temperature. Figure 8(a) shows a room temperature

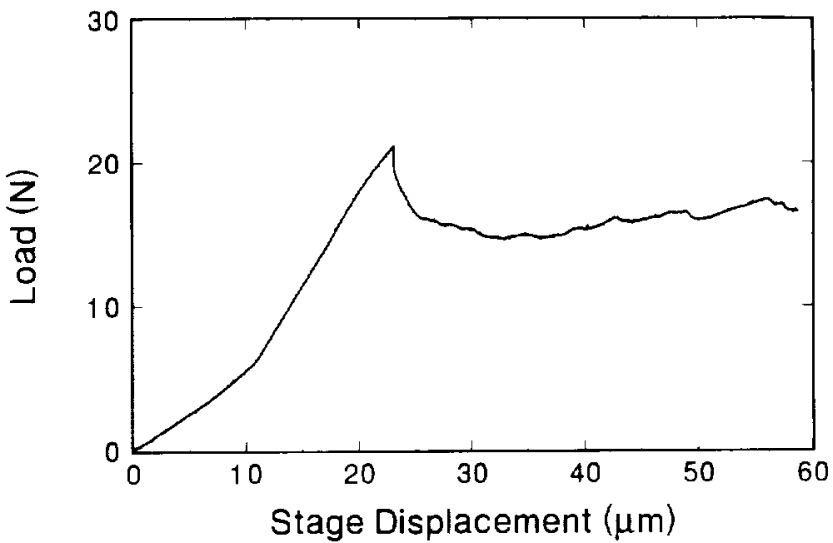

(a)

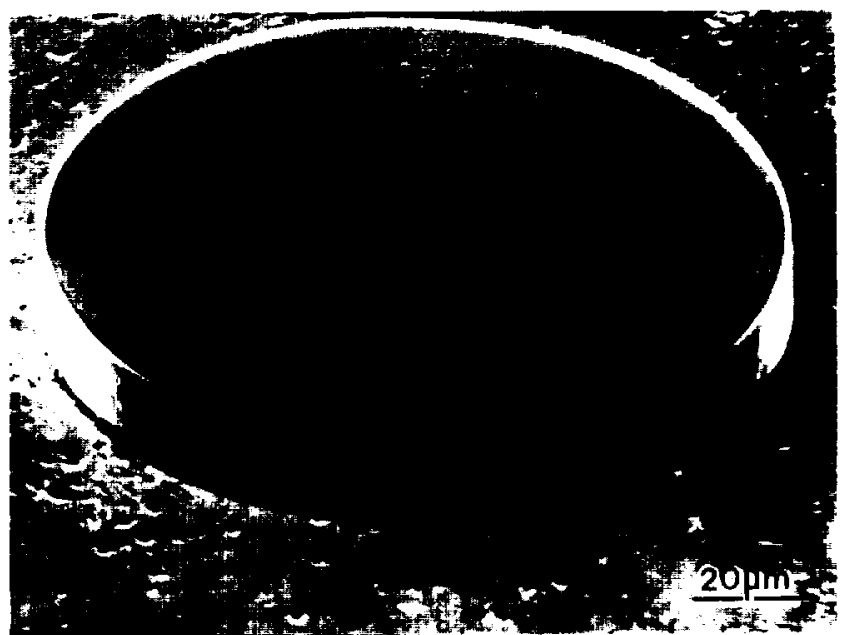

(b)

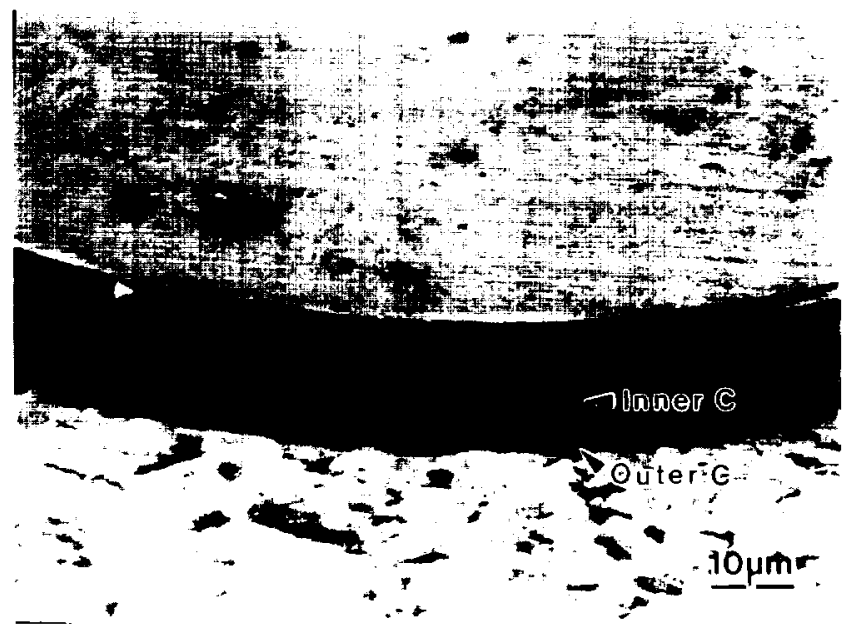

(c)

FIG. 7. (a) Fiber pushout curve for composite intiltrated with Si-2 at. \% Nb alloy (sample thickness $=0.65 \mathrm{~mm}$ ) and $(b, c)$ micrographs showing pushed tibers.

flexural stress versus displacement curve for the $\mathrm{Si}-2$ at. \% niobium alloy infiltrated composite. The average 


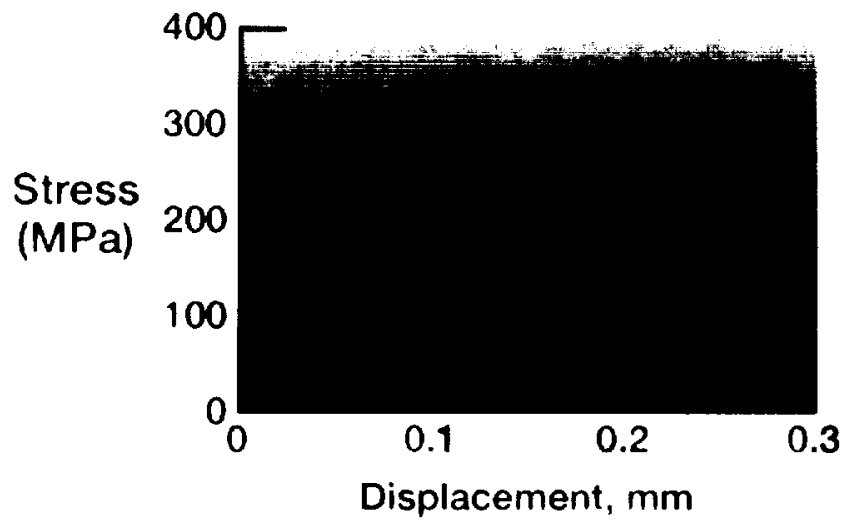

(a)

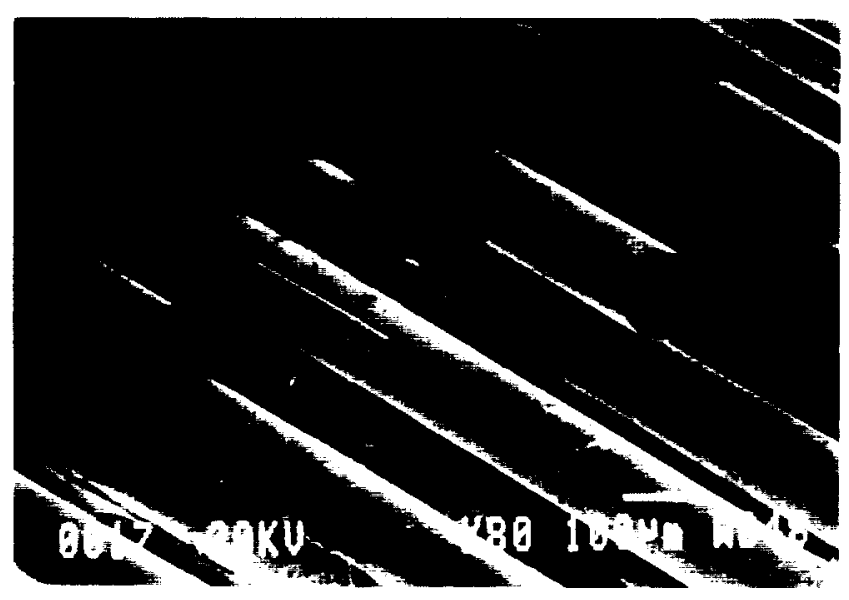

(b)

FIG. 8. (a) Load-deflection curve for $\mathrm{Si}-2$ at. \% niobium alloy infiltrated composites, and (b) fractrograph showing tough composite behavior.

room temperature flexural strength of composites with $\sim 18$ vol \% fibers is $297 \mathrm{MPa}(43.1 \mathrm{KSi})$. The stress-displacement curve [Fig. 8(a)] shows "nonelastic deflection" or strain behavior in these composites, demonstrating an improvement in toughness of these composites due to addition of fibers. The fractograph in Fig. 8(b) also shows fiber pullout and tough composite behavior

\section{SUMMARY}

The microscopic and EMPA results indicate that the niobium from the silicon-niobium alloy precipitates as niobium disilicide $\left(\mathrm{NbSi}_{2}\right)$ in the matrix. There was no evidence of niobium carbide $\left(\mathrm{NbC}, \mathrm{Nb}_{2} \mathrm{C}\right)$ formation at the interface. The silicon carbide matrix has a bimodal grain size distribution with grain sizes in the range of $1-5 \mu \mathrm{m}$ (large grains) and approximately $30 \mathrm{~nm}$ (small grains).

Fiber pushout tests indicate that the majority of fibers debond between the inner and outer carbon layers of the $\mathrm{SiC}$ fibers (SCS-6). The average debond stress was $67.2 \pm 15.1 \mathrm{MPa}$ and the frictional stress was $60.8 \pm$ $14 \mathrm{MPa}$. The room temperature flexural strength of this composite with $\sim 18$ vol \% fibers is $297 \mathrm{MPa}(43.1 \mathrm{KSi})$. Fractographs show fiber pullout and tough composite behavior.

\section{CONCLUSIONS}

The findings of this microstructural and mechanical property study suggest that dense SiC fiber (SCS-6) reinforced-reaction-formed silicon carbide matrix composites can be fabricated by the reaction-forming process without the need for any additional interface coating on the SCS-6 fibers. Minimal damage to the fiber coating has been attributed to the formation of a thin carbon coating on fibers during processing and the microstructural uniformity of the precursor carbon matrix in the preform. In addition, the silicon-niobium alloy infiltrant results in the formation of a uniformly distributed niobium disilicide phase which could be advantageous in improving the fracture toughness of the matrix. Residual free silicon is also uniformly distributed throughout the silicon carbide matrix. This composite shows tough composite behavior through fiber pullout.

\section{ACKNOWLEDGMENTS}

We wish to thank Mr. R.F. Dacek, Frank Terepka, and Todd Leonhardt for their help in the experimental work.

\section{REFERENCES}

1. E. Fitzer and R. Gadow, Am. Ceram. Soc. Bull. 65 (2), 325-335 (1986).

2. D. C. Larsen, J. Adams, L. Johnson, A. Teotia, and L. Hill, Ceramic Materials for Heat Engines (Noyes Publications, NJ. 1985).

3. H. Kodama, H. Sakamoto, and T. Miyoshi, J. Am. Ceram. Soc. 72 (4), $551-558$ (1989).

4. T. Miyoshi, H. Kodama, H. Sakamoto, A. Gotoh, and S. lijima, Metall. Trans. 20A (11), 2419-2423 (1989).

5. F. I. Hurwitz, NASA-TM 105754 (1992).

6. P.J. Lamicq, G. A. Bernhart, M. M. Dauchier, and J.G. Mace, Am. Ceram. Soc. Bull. 65 (2), 336-338 (1986).

7. K. Luthra. R. N. Singh, and M. Brun, in High Temperature Ceramic Matrix Composites, edited by R. Naslain, J. Lamon, and D. Doumeingts (Woodhead Publishing Ltd., 1993), pp. 429-436.

8. R. W. Rice, AIChE J. 36 (4), 481-510 (1990).

9. W. Curtin, J. Eldridge, and G. Srinivasan, J. Am. Ceram. Soc. 76 (9). 2300-2304 (1993).

10. M. Singh and S. R. Levine, NASA TM-107001 (1995),

11. M. Singh, R. M. Dickerson. F. A. Olmstead, and J. I. Eldridge, in 97th Anntual Meeting of the American Ceramic Societn: Cincinnati, OH, May I-3, 1995.

12. M. Singh, unpublished work.

13. J. I. Eldridge, NASA-TM-105341 (1991).

14. Handbook of Binary Alloy Phase Diagrams (American Society of Metals, Metals Park, OH, 1990). 